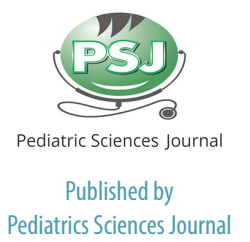

Pediatrics Sciences Journal

\title{
Relationship of Epidermal Growth Factor (EGF) and Insulin-Like Growth Factor-1 (IGF-1) levels in breast milk colostrum with the occurrence of necrotizing enterocolitis in neonates
}

\author{
Anik Puryatni ${ }^{1 *}$, Prasetya Ismail ${ }^{1}$, Fireka Juniantika ${ }^{1}$, Bayu Kurniawan ${ }^{1}$
}

${ }^{1}$ Division of Nutrition and Metabolic Diseases, Department of Pediatrics, Faculty of Medicine, Universitas Brawijaya, Saiful Anwar Hospital, Malang, East Java, Indonesia

\footnotetext{
*Corresponding to: Anik Puryatni; Division of Nutrition and Metabolic Diseases, Department of Pediatrics, Faculty of Medicine, Universitas Brawijaya, Saiful Anwar Hospital, Malang, East Java, Indonesia anik26.fk@ub.ac.id
}

Received: 2021-10-21

Accepted: 2021-12-02

Published: 2021-12-10

\section{ABSTRACT}

Background: Colostrum contains various bioactive compounds that have various roles and potentials in preventing the occurrence of necrotizing enterocolitis (NEC). EGF and IGF-1 are growth factors found in breast milk colostrum in the form of polypeptides that play a role in regulating and stimulating cell proliferation and differentiation processes. The purpose of this study was to determine the relationship between EGF and IGF-1 levels in breast milk colostrum with the occurrence of NEC in neonates.

Methods: This analytical observational study was conducted at Saiful Anwar Hospital Malang during June-August 2019 on mothers and neonates who were breastfed. Maternal colostrum was collected at 72 hours postpartum, while NEC incidence in infants was determined prospectively. EGF and IGF-1 levels in colostrum were examined using the ELISA method. The data were processed by SPSS 21 program and analyzed using Spearman's test and logistic regression.

Results: 24 mother and baby pair samples were included in the study. The mean level of EGF in maternal colostrum was $466 \pm 304 \mathrm{ng} / \mathrm{ml}$, and the mean level of IGF-1 was $1.99 \pm 0.96 \mathrm{ng} / \mathrm{ml}$ with no significant difference in levels based on gestational age. There is a strong negative correlation between the levels of EGF $(r=-0.630 ; p=0.001)$ and IGF- $1(r=-0.646$; $p=0.001)$ on the occurrence of NEC. With the regression test, there was no significant effect between the levels of IGF-1 ( $p=0.995)$ and EGF ( $p=0.997)$ on NEC occurrence.

Conclusion: EGF and IGF-1 levels have a significant relationship to the occurrence of NEC. The higher levels of EGF and IGF-1 contained in breast milk colostrum reduced the incidence of necrotizing enterocolitis in neonates.

Keywords: Colostrum, EGF, IGF-1, NEC.

Cite This Article: Puryatni. A., Ismail, P., Juniantika, F., Kurniawan, B. 2021. Relationship of Epidermal Growth Factor (EGF) and Insulin-Like Growth Factor-1 (IGF-1) levels in breast milk colostrum with the occurrence of necrotizing enterocolitis in neonates. Pediatrics Sciences Journal 2(2): 48-52.

\section{INTRODUCTION}

For newborns, breast milk is the most vital and well-balanced source of nutrition. Nutrients, vitamins, minerals, and bioactive compounds like as hormones, cytokines, and growth factors are all found in breast milk. Breast milk contains a lot of growth factors, which affect the digestive tract, blood vessels, neurological system, and endocrine system biologically. ${ }^{1,2}$ These elements help to regulate the maturation of the intestinal mucosal barrier and aid in the development of digestive function. An additional benefit of their physiological function is that some of these factors can stimulate the repair and healing process of the injured intestinal epithelium.

Necrotizing enterocolitis (NEC) is a multifactorial syndrome of acute intestinal ischemic necrosis, one of the causes of gastrointestinal emergencies in neonates. NEC incidence is 1 per 1000 live births (5\%-10\%), and more than $90 \%$ occurs in premature infants. NEC attacks thousands of newborns every year with more than $40 \%$ mortality. ${ }^{3,4}$ Premature birth, formula feeding, hypoxemic circumstances, and aberrant bacterial colonization are all known risk factors for NEC. ${ }^{5}$

Because the gastrointestinal system serves as a barrier to the outside world, the epithelium must be regenerated on a regular basis. Various chemicals found in breast milk regulate and regulate these activities. ${ }^{3}$ Breast milk is the most effective strategy in protecting infants against NEC. Breast milk has various bioactive compounds that have various roles and potentials in preventing the occurrence of necrotizing enterocolitis (NEC). EGF and IGF-1 are growth factors found in breast milk in the form of polypeptides that play a role in regulating and stimulating cell proliferation and differentiation processes.

One of the growth factors contained in breast milk is epidermal growth factor (EGF). EGF polypeptide increases the 
proliferation and differentiation of several cell types, including intestinal epithelial development, and has trophic, maturation, and healing actions. ${ }^{78}$ Insulin-like Growth Factor-I (IGF-1) is an anabolic hormone with mitogenic, metabolic, differentiation effects, and anti-apoptotic. ${ }^{9}$ IGF-1 also plays a role in enterocyte survival after oxidative stress-induced intestinal damage..$^{10,11}$

Amniotic fluid, breast milk, and saliva are the primary sources of EGF and IGF1. The intestinal mucosa is exposed to EGF in the amniotic fluid during pregnancy, but colostrum and breast milk absorb all sources of EGF after birth. Colostrum has a level of EGF that is 2000 times higher than mature breast milk and 100 times higher than maternal serum. ${ }^{7}$ this study aimed to determine the relationship between EGF and IGF-1 levels in breast milk colostrum with the occurrence of NEC in neonates.

\section{METHODS}

\section{Study Design}

This study is an analytical observational study conducted at Saiful Anwar Hospital Malang from June to August 2019. The affordable population is infants who are treated in the RSSA perinatology room. The research sample was taken by consecutive sampling. Inclusion criteria were neonates treated in the perinatology room of RSSA Malang who received breast milk nutrition, and the mother of the patient allowed her baby to be included in the study after being explained (informed consent). The incidence of NEC in infants was determined prospectively. Pairs of mothers and babies included in the study were followed up until the age limit of 28 days to monitor the presence of NEC. Neonates with congenital or surgical abnormalities of the gastrointestinal tract and neonates who lost follow-up before 28 days of age were excluded from the study.

\section{Sample Collection}

Colostrum samples from mothers were collected at 72 hours postpartum. Breast milk samples were collected manually by being expressed independently in the RSSA perinatology room. The breast milk sample was put in a glass bottle provided by the researcher as much as $\pm 50 \mathrm{ml}$. Glass bottles that have been filled with expressed breast milk will be coded and stored in a special container that contains ice packs to maintain the temperature stability. The samples were then sent to the Biochemistry Laboratory, Faculty of Medicine, Universitas Brawijaya Malang, within $<4$ hours to be stored in the refrigerator for breast milk samples at $-20^{\circ} \mathrm{C}$ prior to analysis. EGF levels in breast milk were measured using the enzyme-linked immunosorbent assay (ELISA) method using the quantitative ELISA Kit. The principle of this assay uses a competitive enzyme immunoassay technique.

\section{Data Analysis}

The data that has been collected is processed with the SPSS 21 program.

Table 1. Correlation Coefficient

\begin{tabular}{cc}
\hline Coefficient Interval & Level of Association \\
\hline $0.00-0.199$ & Very Low \\
$0.20-0.399$ & Low \\
$0.40-0.599$ & Moderate \\
$0.60-0.799$ & Strong \\
$0.80-1.000$ & Very Strong \\
\hline
\end{tabular}

Table 2. Characteristics of Respondents

\begin{tabular}{|c|c|c|c|}
\hline \multicolumn{2}{|l|}{ Variable } & \multirow{2}{*}{$\frac{\mathbf{n}}{21}$} & \multirow{2}{*}{$\begin{array}{c}\% \\
87.5\end{array}$} \\
\hline Maternal age & 17 - 35 years & & \\
\hline & $>35$ years & 3 & 12.5 \\
\hline \multirow[t]{4}{*}{ Level of Education } & Elementary & 4 & 16.7 \\
\hline & Junior High & 5 & 20.8 \\
\hline & Senior High & 6 & 25.0 \\
\hline & Bachelor Degree & 9 & 37.5 \\
\hline \multirow[t]{2}{*}{ Delivery } & Spontaneous & 9 & 37.5 \\
\hline & Caesarian & 15 & 62.5 \\
\hline \multirow[t]{4}{*}{ Parity } & Primipara & 4 & 16.7 \\
\hline & Multipara & 8 & 33.3 \\
\hline & 3 & 9 & 37.5 \\
\hline & 4 & 3 & 12.5 \\
\hline \multirow[t]{2}{*}{ Hypertension } & Yes & 7 & 29.2 \\
\hline & No & 17 & 70.8 \\
\hline \multirow[t]{2}{*}{ Gender of Infant } & Male & 8 & 33.3 \\
\hline & Female & 16 & 66.7 \\
\hline \multirow[t]{4}{*}{ Gestational Age } & $>37$ weeks & 6 & 25 \\
\hline & 32-37 weeks & 6 & 25 \\
\hline & 28-32 weeks & 6 & 25 \\
\hline & $<28$ weeks & 6 & 25 \\
\hline \multirow[t]{2}{*}{ Sepsis } & No & 14 & 58.3 \\
\hline & Yes & 10 & 41.7 \\
\hline \multirow[t]{2}{*}{ NEC } & No & 20 & 83.3 \\
\hline & Yes & 4 & 16.7 \\
\hline
\end{tabular}

The normality test of the data in this study uses the Kolmogorov Smirnov using the Spearman correlation test with $p<0.05$, while the magnitude of the effect was assessed using logistic regression. The level of correlation using the guidelines is in the table.

\section{RESULT}

Twenty-four samples of mother and baby pairs were included in the study with a normally distributed data distribution based on the Kolmogorov Smirnov test. The mean level of EGF in maternal colostrum was $466 \pm 304 \mathrm{ng} / \mathrm{ml}$, and the average level of IGF-1 was $1.99 \pm 0.96 \mathrm{ng} /$ $\mathrm{ml}$. The highest EGF level was found in test. Correlation analysis was carried out 
colostrum at term (>37 weeks), 776.26 ng/ $\mathrm{ml}$ and the lowest level was at 32-37 weeks gestation, which was $162.38 \mathrm{ng} / \mathrm{ml}$. There was no significant difference in EGF levels based on gestational age with $\mathrm{p}=0.223$. The highest level of IGF-1 was found in colostrum with gestational age at term $(>37$ weeks), namely $2.67 \mathrm{ng} / \mathrm{ml}$, and the lowest level at $<28$ weeks gestation, namely 1.65 $\mathrm{ng} / \mathrm{ml}$. There was no significant difference in IGF-1 levels based on gestational age with $p=0.074$. The characteristics of the sample are summarized in Table 2. Levels of EGF and IGF-1 at each gestational age are shown in Figure 1.

There is a significant correlation between EGF levels and NEC occurrence $(p=0.001)$ with a relationship value of $r=-0.630$, which means that a negative correlation is obtained with a strong category. The higher the level of EGF in breast milk colostrum, the lower the incidence of NEC in neonates. It also applies to the results of IGF-1 levels where there is a significant correlation between IGF-1 levels and the occurrence of NEC

\section{Table 3. Correlation of EGF and IGF-1 Levels on the Occurrence of NEC}

\begin{tabular}{lcccc}
\hline \multicolumn{1}{c}{ Variable } & & r & p & Information \\
\hline IGF-1 $(\mathrm{ng} / \mathrm{mL})$ & NEC & -0.646 & 0.001 & Significant \\
EGF $(\mathrm{ngm} / \mathrm{L})$ & NEC & -0.630 & 0.001 & Significant \\
\hline
\end{tabular}

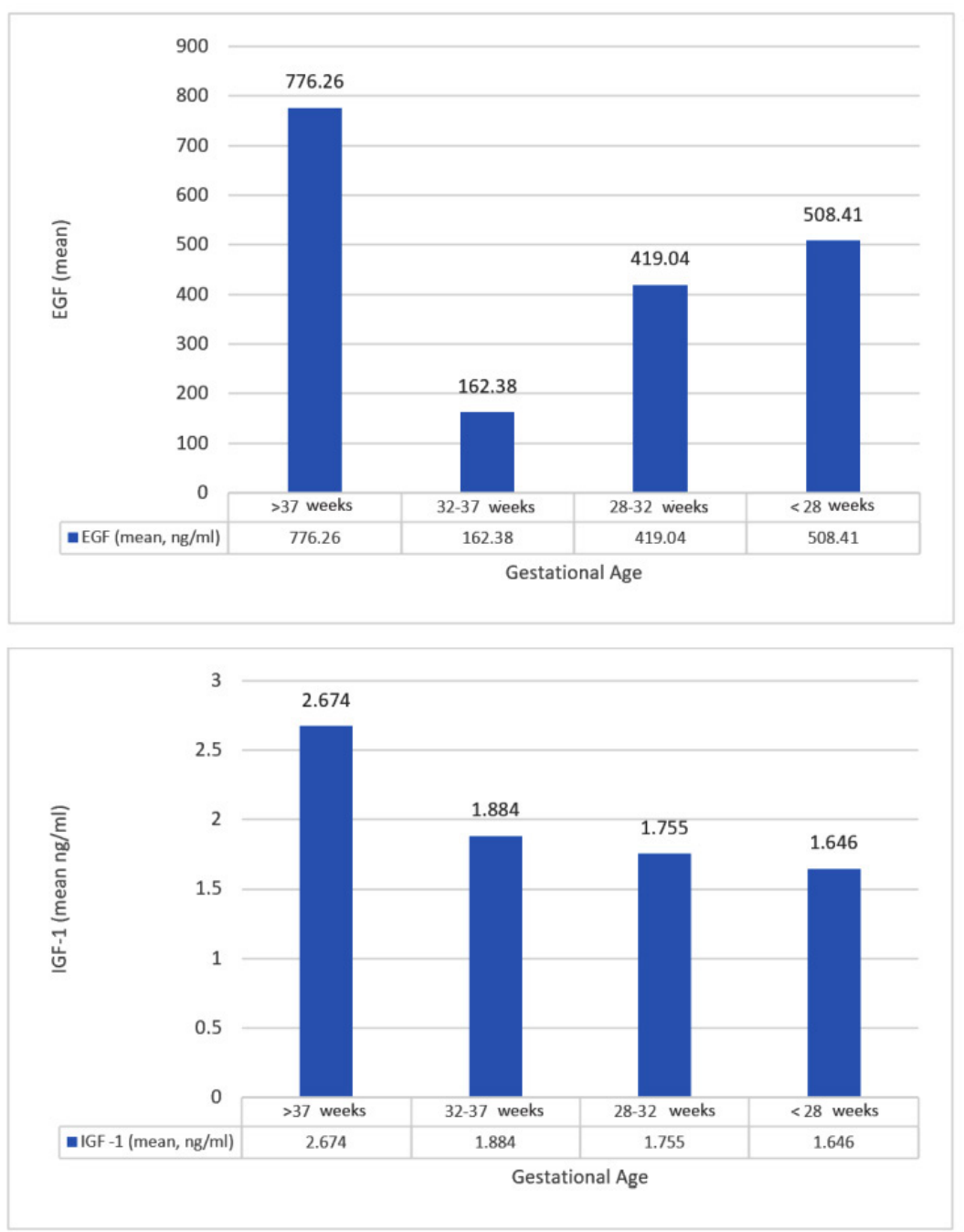

Figure 1. The levels of EGF and IGF-1 at each gestational age

( $\mathrm{p}=0.001)$ with a relationship value of $r=-0.646$, which means that a negative correlation is obtained with a strong category. The higher the level of IGF-1 in breast milk colostrum, the lower the incidence of NEC in neonates.

In this study, regression analysis was used to determine the effect of the independent variable levels of IGF and EGF on the occurrence of NEC. Based on logistic regression analysis, it was found that the levels of EGF and IGF-1 had no significant effect on the occurrence of NEC with $p=0.997$ for EGF and $p=0.995$ for IGF-1. It indicates that low EGF and IGF-1 are not the main cause of NEC in neonates.

\section{DISCUSSION}

In the neonatal period, necrotizing enterocolitis (NEC) is a gastrointestinal emergency. In NEC, clinical manifestations can progress rapidly to intestinal wall necrosis, perforation, peritonitis, organ failure, to sepsis. Therefore, prevention is very important in handling NEC. ${ }^{5}$ Breast milk can effectively prevent the occurrence of NEC by containing growth factors in it. EGF and IGF-1 are growth factors with high concentrations in breast milk, especially colostrum. ${ }^{5}$

EGF levels in breast milk are highest on the first day of lactation (physiological dose of EGF $100 \mathrm{ng} / \mathrm{ml}$ ) and gradually drop throughout the first month of lactation. $^{3,7}$ Surprisingly, EGF levels in premature newborns are $50-80 \%$ higher than in term neonates' mothers' breast milk. In a 2006 study by Clark, EGF levels in breast milk with premature infants were $50-80 \%$ higher than those with term infants. ${ }^{7}$ Some opinions suggest that this is a compensation for the protective effect against NEC incidence, which is more common in premature infants. ${ }^{3,7}$ In this study, the mean EGF level in maternal colostrum was $466 \pm 304 \mathrm{ng} / \mathrm{ml}$, with the highest EGF level found in colostrum at term ( $>37$ weeks) and the lowest level at 32-37 weeks gestation. Significant levels of EGF in term and preterm neonates. Unlike Warner et al., in their study of EGF levels in mature and premature infants, EGF concentration correlates with gestational age and increases postnatally. ${ }^{12}$ However, several studies have stated that there is 
no significant difference between preterm and mature milk. ${ }^{10,13}$ In another study, the concentration of EGF in premature infants' breast milk ranged from $70 \pm 5 \mathrm{ng} /$ $\mathrm{ml}($ mean \pm SEM) to $68 \pm 19 \mathrm{ng} / \mathrm{ml}$ (mean \pm SEM), with no significant difference in these amounts based on gestational age. ${ }^{8}$

IGF-1 levels increase with gestational age during pregnancy and correlate with the fetal size and fat mass. ${ }^{9}$ In this study, the average IGF-1 level was $1.99 \pm 0.96 \mathrm{ng} /$ $\mathrm{ml}$. The highest levels of IGF- 1 were found in colostrum with a gestational age of $>37$ weeks and the lowest levels at $<28$ weeks of gestation. It was seen that IGF-1 levels increased with gestational age, although the results were not significant.

In this study, there was a strong negative correlation between EGF and IGF-1 on the occurrence of NEC. The higher levels of EGF and IGF-1 contained in breast milk colostrum reduced the incidence of necrotizing enterocolitis in neonates. Warner, in his research on EGF levels in mature and premature infants, showed that low levels of EGF received by infants were associated with an increased incidence of NEC. ${ }^{14}$

EGF protects the intestine from NEC by a complicated strategy that includes lowering inflammation, balancing intestinal tight junctions, balancing epithelial apoptosis, and blocking autophagy in lesions. ${ }^{15}$ Meanwhile, IGF-1 interacts with inflammatory factors, which have unique physiological functions, including stimulating growth and development of the gastrointestinal tract and stimulating healing of injured intestinal tissue. ${ }^{5}$

Various studies have demonstrated the role of EGF in maintaining intestinal organ barrier function, increasing intestinal enzyme activity, and improving nutrient transport processes. Dvorak and Clark's study showed that EGF reduces NEC incidence in mouse models by inhibiting apoptosis and barrier damage. ${ }^{12}$

The biologic action of EGF is mediated by specific binding to EGF-R distributed throughout the infant's gastrointestinal tract. ${ }^{7}$ EGF stimulates gastrointestinal mucosal cell recovery and proliferation, influences gastrointestinal adaptation to irritating substances, mediates healing of acute and chronic lesions, and inhibits gastric acid secretion. ${ }^{7,16}$ Enteral nutrition induces changes in intestinal function and structure. One study found changes in EGF-R expression within 24 hours after asphyxia or cold stress conditions. EGF is not contained in formula milk so that the neonate's gastrointestinal tract loses the opportunity to be exposed to various biologically active factors making it susceptible to damage and NEC. ${ }^{3,7}$

EGF may pass through the stomach and into the intestine because it is resistant to low $\mathrm{pH}$ and digestive enzymes. It stimulates enterocytes to accelerate DNA synthesis, cell division, water and glucose absorption, and protein synthesis. ${ }^{16,17}$ EGF has a strong effect on specific cell differentiation in vivo. Moreover, it is a potent mitogenic factor for cultured cell varieties of either ectodermal or mesodermal origin. EGF precursors are believed to be present in membrane-bound molecules that cleave proteolytically for a generation. ${ }^{17}$ EGF has various protective mechanisms in the gut of newborns, including the suppression of programmed cell death and the repair of tight junction proteins in the intestine and liver of infants caused by the proinflammatory cytokine TNF- $\alpha{ }^{18,19}$

IGF-1 plays a key role in the survival of premature infants with low serum IGF-I levels, which have been linked to an increased risk of a variety of diseases, including retinopathy of prematurity and NEC. Breastfed babies had increased IGF-I levels in their blood. ${ }^{20}$ The gut can absorb Insulin-like Growth Factor-I in a bioactive state and transfer it into the bloodstream. ${ }^{18}$ IGF-I also exhibits protective effects during inflammation and driven apoptosis. by cytokine..$^{18,21}$

In an experimental study conducted by Tian et al., it was proved that enteral administration of IGF-1 at physiological levels could improve clinical manifestations of NEC in mouse models and reduce NEC's incidence. The mechanism thought to play a role in this is that IGF-1 can suppress the expression of TLR4 mRNA to inhibit the production of inflammatory mediators and stimulate the expression of MUC2 and SigA to protect the mechanical and immunological barrier function of the intestinal mucosa. bowl resection of baby rats with NEC showed an increase in IGF-
1 receptors. ${ }^{22,23}$

In this study, although there was a very strong relationship between EGF and IGF-1 levels on NEC occurrence, neither of them was proven to be significant as a cause of NEC in neonates. EGF and IGF levels are not the only determinants of NEC occurrence. Breast milk has various bioactive compounds that have various roles and potentials in preventing the occurrence of necrotizing enterocolitis (NEC). Various growth factors and other cytokines play a role in it. Various risk factors have contributed to the confounding of the protective effect.

\section{CONCLUSION}

EGF and IGF-1 levels have a significant relationship to the occurrence of NEC. The higher levels of EGF and IGF-1 in breast milk colostrum reduced the incidence of necrotizing enterocolitis in neonates, although the levels of these two growth factors were not the main determinants of NEC occurrence. Efforts to support breastfeeding, especially colostrum, are expected to reduce morbidity and mortality in infants. Also, further research with larger samples and different study designs needs to be done to identify the root causes occurrence of NEC in neonates.

\section{FUNDING}

There are no funding sources, grants, or third-party support.

\section{CONFLICT OF INTEREST}

None of the authors have a conflict of interest to declare.

\section{AUTHOR CONTRIBUTION}

All Authors were involved in concept formulating, designing, and supervising the manuscript. All authors analyzed the data, prepared the manuscript, and agreed to this final version of the manuscript submitted to this journal.

\section{ETHICAL CONSIDERATION}

This study has been approved by the Health Research Ethics Committee of the Faculty of Medicine, Universitas Brawijaya. 


\section{REFERENCES}

1. Ballard O, Morrow AL. Human milk composition: nutrients and bioactive factors. Pediatr Clin North Am. 2013;60(1):49-74. Available from: https://pubmed.ncbi.nlm.nih. gov/23178060

2. Andreas NJ, Kampmann B, Mehring LeDoare K. Human breast milk: A review on its composition and bioactivity. Early Hum Dev. 2015;91(11):629-35. Available from: http:// dx.doi.org/10.1016/j.earlhumdev.2015.08.013

3. Dvorak B. Milk epidermal growth factor and gut protection. J Pediatr. 2010;156(2 Suppl):S31-5. Available from: https://pubmed.ncbi.nlm.nih. gov/20105663

4. Sidauruk RJM, Amir I, Kadim M, Said M. Faktor Risiko yang Memengaruhi Kolonisasi Mikroflora Saluran Cerna Neonatus Kurang Bulan dengan Enterokolitis Nekrotikans. Sari Pediatr. 2016;15(6):353. Available from: http:// dx.doi.org/10.14238/sp15.6.2014.353-60

5. Tian F, Liu GR, Li N, Yuan G. Insulin-like growth factor I reduces the occurrence of necrotizing enterocolitis by reducing inflammatory response and protecting intestinal mucosal barrier in neonatal rats model. Eur Rev Med Pharmacol Sci. 2017;21(20):4711-9.

6. Herrmann K, Carroll K. An exclusively human milk diet reduces necrotizing enterocolitis. Breastfeed Med. 2014/03/03. 2014;9(4):184-90. Available from: https://pubmed.ncbi.nlm.nih. gov/24588561

7. Clark J. The Protective Role of Epidermal Growth Factor in Neonatal Necrotizing Enterocolitis In the Graduate College. The University of Arizona; 2006.

8. Moran JR, Courtney ME, Orth DN, Vaughan R, Coy S, Mount CD, et al. Epidermal growth factor in human milk: Daily production and diurnal variation during early lactation in mothers delivering at term and at premature gestation. J Pediatr. 1983;103(3):402-5.

9. Alzaree FA, AbuShady MM, Atti MA, Fathy GA, Galal EM, Ali A, et al. Effect of Early Breast Milk Nutrition on Serum Insulin-Like Growth Factor-1 in Preterm Infants. Open access Maced
J Med Sci. 2019;7(1):77-81. Available from: https://pubmed.ncbi.nlm.nih.gov/30740165

10. Elmlinger MW, Hochhaus F, Loui A, Frommer KW, Obladen M, Ranke MB. InsulinLike Growth Factors and Binding Proteins in Early Milk from Mothers of Preterm and Term Infants. Horm Res Paediatr. 2007;68(3):124-31. Available from: http:// dx.doi.org/10.1159/000100488

11. Baregamian N, Song J, Chung DH. Effects of oxidative stress on intestinal type I insulinlike growth factor receptor expression. Eur J Pediatr Surg. 2012/03/20. 2012;22(1):97-104. Available from: https://pubmed.ncbi.nlm.nih. gov/22434232

12. Caplan M. Is EGF the Holy Grail for NEC? J Pediatr. 2007;150(4):329-30. Available from: http://dx.doi.org/10.1016/j.jpeds.2007.01.027

13. Blum JW, Baumrucker CR. Colostral and milk insulin-like growth factors and related substances: Mammary gland and neonatal (intestinal and systemic) targets. Domest Anim Endocrinol. 2002;23(1-2):101-10. Available from: $\quad$ http://dx.doi.org/10.1016/s07397240(02)00149-2

14. Warner BW, Warner BB. Role of epidermal growth factor in the pathogenesis of neonatal necrotizing enterocolitis. Semin Pediatr Surg. 2005;14(3):175-80. Available from: http:// dx.doi.org/10.1053/j.sempedsurg.2005.05.006

15. Coursodon CF, Dvorak B. Epidermal growth factor and necrotizing enterocolitis. Curr Opin Pediatr. 2012;24(2):160-4. Available from: http://dx.doi.org/10.1097/ mop.0b013e3283504ddb

16. Maynard AA, Dvorak K, Khailova L, Dobrenen $\mathrm{H}$, Arganbright $\mathrm{KM}$, Halpern $\mathrm{MD}$, et al. Epidermal growth factor reduces autophagy in intestinal epithelium and in the rat model of necrotizing enterocolitis. Am J Physiol Gastrointest Liver Physiol. 2010/06/10. 2010;299(3):G614-22. Available from: https:// pubmed.ncbi.nlm.nih.gov/20539009

17. Carlson S, Korones. S, Werkman S, Montalto $\mathrm{M}$, Ponder D. Lower Incidence of Necrotizing Enterocolitis in Infants Fed a Preterm Formula with Egg Phospholipids [Internet]. Nutrition and Biochemistry of Phospholipids. AOCS Publishing; 2003. Available from: http://dx.doi. org/10.1201/9781439822128.ch19

18. Rowland KJ, Choi PM, Warner BW. The role of growth factors in intestinal regeneration and repair in necrotizing enterocolitis. Semin Pediatr Surg. 2013;22(2):101-11. Available from: https://pubmed.ncbi.nlm.nih. gov/23611614

19. Khailova L, Dvorak K, Arganbright KM, Halpern MD, Kinouchi T, Yajima $M$, et al. Bifidobacterium bifidum improves intestinal integrity in a rat model of necrotizing enterocolitis. Am J Physiol Gastrointest Liver Physiol. 2009;297(5):G940-9. Available from: https://pubmed.ncbi.nlm.nih.gov/20501441

20. Büyükkayhan, Tanzer, Erselcan, Çinar, Yönem. Umbilical Serum Insulin-like growth Factor 1 (IGF-1) in Newborns: Effects of Gestational Age, Postnatal Age, and Nutrition. Int J Vitam Nutr Res. 2003;73(5):343-6. Available from: http://dx.doi.org/10.1024/0300-9831.73.5.343

21. Allen NE, Roddam AW, Allen DS, Fentiman IS, Dos Santos Silva I, Peto J, et al. A prospective study of serum insulin-like growth factor-I (IGF-I), IGF-II, IGF-binding protein-3 and breast cancer risk. Br J Cancer. 2005;92(7):12837. Available from: https://pubmed.ncbi.nlm. nih.gov/15756268

22. Ozen S, Akisu M, Baka M, Yalaz M, Sozmen EY, Berdeli A, et al. Insulin-Like Growth Factor Attenuates Apoptosis and Mucosal Damage in Hypoxia/Reoxygenation-Induced Intestinal Injury. Neonatology. 2005;87(2):91-6. Available from: http://dx.doi.org/10.1159/000081897

23. Baregamian N, Song J, Papaconstantinou J, Hawkins HK, Evers BM, Chung DH. Intestinal mitochondrial apoptotic signaling is activated during oxidative stress. Pediatr Surg Int. 2011/03/13. 2011;27(8):871-7. Available from: https://pubmed.ncbi.nlm.nih.gov/21400030

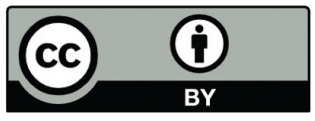

This work is licensed under a Creative Commons Attribution 